\title{
Percurso Semântico do Tema Empregabilidade: a (Re)Construção de Parte da História de uma Empresa de Telefonia
}

\author{
Alexandre de Pádua Carrieri \\ Amyra Moyzes Sarsur
}

\begin{abstract}
Resumo
Este artigo é resultado de dez anos de pesquisa sobre as transformações das significações culturais em uma empresa do setor de telecomunicações. Na pesquisa, diversos percursos semânticos foram analisados. Para este trabalho, foi estudado o percurso discursivo do tema empregabilidade. Este tema foi escolhido partindo-se da idéia de que empregabilidade representaria uma estratégia adotada pela alta administração das empresas, no sentido de transferência da organização para o trabalhador da responsabilidade da não-contratação ou da demissão. Utilizando-se a Análise dos Discursos, foram analisadas cerca de cem entrevistas realizadas com gerentes e técnicos, empregados e exempregados, e efetuada análise documental da empresa pesquisada, estruturando-se o estudo do percurso discursivo do tema empregabilidade. No exame dos dados, observaram-se três fases de estruturação do tema: a primeira, somente como discurso da alta administração; a segunda, como tema compartilhado pela alta administração e pela gerência; e a terceira, como tema disseminado entre todos os atores organizacionais. Por fim, pode-se também observar que o percurso semântico da empregabilidade evidenciou o enfraquecimento progressivo do pacto da estabilidade-fidelidade dos empregados na empresa investigada.
\end{abstract}

Palavras-chaves: empregabilidade; análise do discurso; estratégia organizacional.

\begin{abstract}
This article is a result of ten years of research on the transformations of the cultural significances in a company of the telecommunications sector. In the research, several semantic paths were analyzed. For this work, it was studied the discursive course of the theme employability. This theme was chosen based on the idea that employability would represent a strategy adopted by the high administration of the companies, in the sense of transferring the organization to the worker - the responsibility of the non-recruiting, or, of the dismissal. With the critical analysis of speeches, some hundred of interviews - conducted with managers and technicians, employees and former-employees, and a documental analysis of the studied company - were analyzed, therefore structuring the research of the discursive course of the theme employability. In the analysis of the data, three structuring phases were observed: the first one was only seen as a speech of the high administration; the second, regarded as theme shared by the high administration and by the management; and the third one, was seen as theme disseminated among all the organizational actors. Finally, it can also be observed that the semantic course of the employability evidenced a progressive weakness of the stability-fidelity pact among the employees and the researched company.
\end{abstract}

Key words: employability; speech analysis; organizational strategy. 


\section{INTRODUÇÃO}

Este artigo buscou analisar o percurso discursivo do tema empregabilidade. Parte-se da idéia de que as mudanças observadas no cenário mundial têm imposto desafios crescentes às organizações, que os repassam aos indivíduos. As pessoas são levadas a buscar o que se denomina como empregabilidade, para inseriremse em mercado cada vez mais competitivo. A idéia de empregabilidade representaria uma estratégia adotada pela alta administração das empresas, no sentido de transferir-se da organização para o trabalhador a responsabilidade da não-contratação ou da demissão. Neste caso, o acesso ou não ao emprego aparece como dependendo da restrita vontade individual de qualificação, quando se sabe que fatores como, por exemplo, o processo de globalização e de abertura econômica do país, contribuem decisivamente para essa situação do trabalhador.

Em seu aspecto simbólico, a globalização pode ser representada como força externa que pressiona os modos de pensar e agir das organizações e dos indivíduos, em conformidade com padrões macroeconômicos determinados pelos países centrais. E é, neste contexto, que a empregabilidade emerge como tema corrente, fomentado pelo discurso da globalização, associada à capacidade de obtenção de trabalho e renda permanente.

É sob enfoque crítico do uso do termo empregabilidade, adotado pelas empresas e absorvido pelos profissionais, que foi elaborado o presente artigo, como forma de responder às indagações: como emerge e ganha força o termo junto a empresas e profissionais, e quais impactos ele tem trazido e ainda poderá trazer sobre as relações estabelecidas entre empregador e empregado.

A abordagem empírica do tema é explicitada por meio dos resultados de pesquisa mais ampla sobre as significações culturais de uma empresa de telecomunicações em Minas Gerais: a Telemig. Reconstruíram-se dez anos da história - de 1990 até 2000 - dessa organização, com base em inúmeros documentos da empresa e do sindicato, que possibilitaram a construção do percurso semântico do tema empregabilidade, e em entrevistas com funcionários, desde a alta gerência até representantes do sindicato, de empregados a ex-empregados. Para a análise dos dados, trabalhou-se com a ferramenta metodológica da Análise do Discurso. Foi escolhido o setor de telecomunicações pelo fato de que este tem passado por muitas modificações em termos de transformação da propriedade e incertezas provenientes das mudanças tecnológicas e da abertura do mercado via privatização em 1998, além de ser considerado um dos segmentos mais competitivos no contexto atual. 


\section{A Globalização: Contextualização Temática}

Embora a utilidade do termo globalização seja altamente contestada pelos diversos significados que engloba, é inevitável considerar a sua influência nas organizações e nas práticas de gestão. As transformações fomentadas pelo processo de globalização no plano concreto das economias e organizações têm sua sustentação no plano simbólico das percepções e significações ${ }^{(1)}$. Ao estudarem o discurso sobre competição, Rodrigues, Carrieri e Luz (2000) evidenciam como isso ocorre. Em suas análises, o discurso internacional sobre competição, que pode abordar desde a produção industrial até o nível de educação da população, é construído por meio de processo de colagem de indicadores. Esse discurso é reelaborado por grupos sociais, que criam novos índices, novos temas e vocábulos. Esse novo debate é, por sua vez, instrumento de transformação organizacional, pois tenta integrar o discurso internacional às narrativas locais. No ambiente organizacional, o processo de globalização e o tema do livre mercado impelem as propostas de reestruturação, caracterizadas pelos programas de qualidade total, reengenharia, downsizing, core business, vantagens competitivas, entre outros. Du Gay, Salaman e Rees (1996) afirmam que, nos anos 1980, nos países centrais, configurou-se um discurso fundador que propunha o tema das reformas e reestruturações organizacionais. O discurso servia de referência a outros discursos que enfatizavam satisfação total do cliente/consumidor, novas competências, empregabilidade etc.

Assim, os temas da ênfase no mercado e no cliente, das novas competências gerenciais e da empregabilidade parecem resolver um tradicional dilema gerencial, qual seja, controlar e direcionar os indivíduos para comportamentos desejados: autonomia, flexibilidade, criatividade, autovigilância, espírito empreendedor etc. Para Freitas (2000, p. 11), nesse discurso, e também nas ações organizacionais, é dito que o indivíduo deve considerar-se como o "empreendedor de sua própria vida", que ele seja o "seu próprio projeto" e que se veja como "um capital que deve dar retorno”, buscando sempre melhorar sua empregabilidade.

\section{O Tema Empregabilidade: Preâmbulo}

Nos últimos anos tem-se configurado o agravamento da crise pela qual passa o universo do trabalho, gerando modificações identificadas, entre outros fatores, pela diminuição do número de empregos formais, pelo aumento dos índices de desemprego e trabalhos informais e precários e, especialmente, 
pelo incremento das exigências quanto à qualificação e formação dos trabalhadores. É dessa maneira que termos como empregabilidade emergem, entendidos como concepções que consolidam e geram concretude à idéia de modificação desse cenário.

O tema tem sido alvo de publicações diversas, nas quais se constata o uso dos mesmos autores de referência, não agregando novidades às discussões já estabelecidas. $\mathrm{O}$ mesmo tende a acontecer com outras publicações referentes a esses aspectos da qualificação e atualização permanente ${ }^{(2)}$. E, ainda, no que se refere à publicação de livros que tendem a abordar a questão do ponto de vista individual, posicionando a empregabilidade como solução para o desemprego; nesse caso, a responsabilidade por estar ou não empregado seria exclusiva do trabalhador ${ }^{(3)}$. Sem tirar o valor agregado com tais obras, observa-se certa idealização do perfil esperado pelo mercado, e que deve, a qualquer custo, ser conquistado pelo trabalhador.

Em face da diversidade de entendimentos e conceitos lançados sobre o termo, que serão apresentados em seguida, tornou-se necessário alinhavar uma idéia única que servisse como referência para o estudo proposto. Assim a empregabilidade é aqui entendida como estratégia adotada pela alta administração das empresas, no sentido de transferir da organização para o trabalhador a responsabilidade da não-contratação ou de possível demissão.

Algumas organizações, como o grupo Catho, desenvolvem um tipo de teste para avaliar a empregabilidade dos profissionais perante as mudanças de mercado. Segundo a análise apresentada, o termo empregabilidade surge para fazer frente a uma nova realidade que começa a despontar, ou seja, para mostrar aos profissionais que eles não deveriam mais pressupor a existência de empregos formais e estáveis.

Bridges (1995, p. 64) afirma que, tendo em vista as novas condições do mercado, sem possibilidades de alcance do emprego formal,

"agora a estabilidade reside na pessoa, e não na posição [...] no futuro, sua estabilidade de emprego dependerá de você desenvolver três características como trabalhador e pessoa: (1) empregabilidade: sua estabilidade virá primeiro e acima de tudo de você ser uma perspectiva atraente para os empregadores, e essa atividade envolve ter as capacidades e atitudes que o empregador precisa no momento".

Ter empregabilidade é conseguir rapidamente emprego em qualquer organização, independentemente do momento em que vive o mercado em termos de maior ou menor demanda. Seriam exemplos de empregabilidade: falar mais de uma língua, 
conhecer e respeitar diferenças culturais e saber tomar decisões dentro de um esquema de globalidade.

Sarsur (1997) comenta que poucas são as pesquisas desenvolvidas que procuram compreender qual tem sido o posicionamento dos profissionais diante dessas mudanças no mundo do trabalho e a relação com o termo empregabilidade. Tal fato indica como ainda é difícil para os profissionais compreenderem a real dimensão da exclusão que tem sido provocada pelas mudanças no interior das empresas. Os indivíduos, apesar de entenderem que as transformações acontecem do ponto de vista da alteração nas formas de se estabelecer o contrato de trabalho, ainda desejam (re)ingressar em organizações que lhes possibilitem a manutenção dos direitos e benefícios próprios do emprego formal.

Somente nos últimos anos, começaram a intensificar-se as críticas com relação ao uso indiscriminado do termo empregabilidade, como alternativa para as questões sobre o desemprego. Algumas delas são aqui apresentadas como forma de fazer contraponto à valorização excessiva que vem sendo dada à responsabilidade individual do trabalhador na relação entre (re)inserção ou exclusão do mercado de trabalho.

De acordo com Bernardes (1994), o fenômeno da mundialização econômica traz à tona a concepção de empresa contemporânea, configurada como ator coletivo, cuja excelência de desempenho está condicionada pela capacidade de coordenação e cooperação entre os atores envolvidos. O foco amplia-se sobre a integração dos diversos setores e valorização da participação, autonomia e qualificação do trabalhador. Há um antagonismo, porém, que se apresenta ao se analisar o discurso da excelência que esbarra na ausência de postos de trabalho, em que tal desempenho possa ser posto em prática, revelando que a problemática central está à margem dessa discussão: trata-se de saber não como ocorre a inserção do homem no processo produtivo, mas como ele se insere efetivamente.

Mendonça (1997) afirma que, nos discursos correntes, a noção de empregabilidade supõe implicitamente uma responsabilidade individual do trabalhador, isolado de mudanças ambientais, deslocando da sociedade e do Estado um dos seus papéis fundamentais.

Neste cenário, no qual predomina a competitividade, antigos valores foram abandonados e novos paradigmas incorporados: no lugar do conhecimento tecnológico, a competência para gerir negócios; no lugar da estabilidade, o discurso da empregabilidade. Competir e cooperar passam a ser exigências simultaneamente impostas, quer no âmbito interno, quer no âmbito externo da empresa. $\mathrm{O}$ trabalho em equipe é estimulado, mas as premiações, promoções e visibilidade são garantidas pelo estímulo ao bom desempenho individual. No sistema capitalista 
avançado (neoliberal), as garantias de emprego são substituídas pela empregabilidade. Com essa estratégia, a organização consegue do indivíduo o comprometimento com seus propósitos, extraindo dele mais trabalho e dedicação. Os laços com a empresa tornam-se, assim, mais fortes e o indivíduo crê que não é dominado pela organização, mas que a domina, na medida em que seu emprego agora depende exclusivamente do próprio esforço. Ele se torna o empresário de si mesmo, de sua carreira, e, neste sentido, acredita ser independente da organização (Luz, 2001).

Desta forma, é necessário estar atento às características apontadas na literatura, entendendo-se que nem tudo o que é apresentado como essencial será alcançado pelos profissionais: o perfil exigido indica uma referência ou modelo ideal. Tal alerta é feito por alguns autores preocupados com o nível de ansiedade causado pela busca interminável por maior qualificação. Gitahy e Fischer (1996, p. 3) afirmam que os profissionais são forçados a buscar um "perfil ideal que reflete uma feroz autocrítica sobre seu próprio desempenho e sugere a construção de um super-homem”; este é o foco da presente discussão.

\section{Percurso Semântico: Caminhos de Apreensão do Tema Empregabilidade}

O percurso discursivo do tema empregabilidade foi estruturado por meio de discursos. Um discurso pode ser entendido como um "conjunto de temas [...] que materializam valores, normas, carências, desejos, explicações, justificativas e racionalizações [isto é,] um conjunto de temas [...] que materializam uma determinada visão de mundo" (Fiorin, 1988, p. 43, 32). Neste sentido, propõe-se um estudo pautado em elementos da Análise do Discurso (AD) como, por exemplo, os percursos temáticos e figurativos, as seleções temática e lexical e a construção das personagens. O uso desses elementos da AD em uma pesquisa possibilita explorar não só as ambigüidades e contradições, mas também os vários modos de representações, os múltiplos valores e a construção das significações da vida organizacional pelos atores envolvidos.

A $\mathrm{AD}$ é instrumento de pesquisa que permite investigar os textos escritos e a interação oral (formal e informal) que se processa nas organizações e entre as pessoas. A AD possibilita, entre outros aspectos, examinar como as significações constituintes de determinada visão de mundo, são articuladas no discurso de quem tem poder de decisão e repassadas para a organização como um todo. Os discursos desempenham papel ativo na passagem do subjetivo (significações dadas pelos atores organizacionais aos processos e práticas gerenciais e à identidade da 
organização) para o objetivo (linguagem escrita e falada), o que os torna uma rica fonte de conhecimentos sobre o contexto organizacional na Teoria das Organizações (TO). Por esse motivo, para este trabalho, a AD é considerada uma ferramenta poderosa na investigação e compreensão do contexto organizacional para a TO.

Como estratégia para a análise deste trabalho, adota-se o que Faria (2001) denomina de percurso semântico, que englobaria os percursos temáticos (e figurativos). Entre os vários percursos semânticos observados na pesquisa, destaca-se o do tema empregabilidade, pois chama atenção a forma como ele foi sendo incorporado, com o passar dos anos, pelos diversos atores organizacionais. Fiorin $(1988,1989)$ afirma que a tematização e a figurativização são elementos semânticos que estão presentes em qualquer formação discursiva. As figuras remeteriam diretamente o discurso para o mundo natural; já os temas, aos elementos abstratos não pertencentes ao mundo natural. Esse mesmo autor afirma que os temas são elementos semânticos presentes em qualquer discurso. Os temas remetem aos elementos abstratos. Os “discursos temáticos têm uma função predicativa ou interpretativa” (Fiorin, 1989, p. 65); eles exercem papel de “categoria ordenadora dos fatos observáveis” (Fiorin, 1988, p. 24), isto é, procuram explicar a realidade, até mesmo estabelecendo relações de dependência. Faria (1999, p. 28-29) argumenta que o discurso "tem de um lado um conjunto de temas [...] articulados e, por outro lado, um conjunto de contradições que mantém com outros discursos”. No primeiro momento, cabe ao pesquisador identificar os temas dos discursos (organizacionais), pois é por meio deles que ocorre a materialização dos valores, dos desejos, das explicações, das justificativas e racionalizações existentes na formação social (organizacional também) na qual os indivíduos estão insertos.

Desse modo, embasado na dimensão metodológica que a AD proporciona, este trabalho foi fundamentado em inúmeros documentos - textos escritos - em especial nos jornais do sindicato O Bode Berra e O Bodim Semanal, e da própria empresa: DDdicas, Jornal Telemar, Construindo a Transformação, entre outros. Além disso, realizou-se um rol de entrevistas, abrangendo desde a alta gerência da organização até o sindicato, de empregados a ex-empregados. Nesse sentido, foram entrevistadas aproximadamente cem pessoas. As entrevistas foram realizadas desde 1998 até 2000. Havia também um estoque de entrevistas coletadas no começo dos anos 1990 mediante a pesquisa de Rodrigues (1991). O levantamento dos discursos (documentos) escritos - um a um ao longo de dez anos - e das entrevistas possibilitou a (re)construção da transformação histórica da Telemig e do percurso semântico do tema empregabilidade dentro dele.

Durante o processo de pesquisa, procurou-se criar uma relação constante entre 
o estoque de conhecimentos à disposição desses atores e as construções teóricas sobre sua realidade. As evidências surgidas são, nas palavras de Schutz (1979), construções de construções, por assim dizer, construções de "segundo grau". Desta maneira, trabalha-se aqui, em outras palavras, "interpretando interpretações”.

\section{A Análise do Discurso: Empregabilidade versus Organização}

$\mathrm{Na}$ análise dos dez anos de dados coletados na Telemig/TelemarMinas, foi possível evidenciar três fases importantes do percurso semântico do tema empregabilidade. A primeira fase remonta ao início dos anos 1990; a segunda fase emerge no período de 1995 até 1998; a terceira e última fase acontece já com a empresa privatizada, a partir de 1998.

\section{Primeira Fase: Empregabilidade Somente como Discurso da Alta Administração}

De maneira geral, na Telemig dos anos 1990/1995 pode-se observar um discurso, aqui denominado empresarial (dito modernizante), que abrange um conjunto de temas como: modernização, imagem pública da empresa, qualidade total, reengenharia, volta para a Bolsa de Valores, profissionalismo, satisfação dos clientes, abertura do setor à competição, mudança de identidade, quebra de paradigmas, empregabilidade. É importante esclarecer que os temas não obedecem necessariamente à ordem citada e, muitas vezes, a mesma personagem é associada a diversos temas. Segundo Fleury, Shinyashiki e Stevanato (1997), os discursos oficiais, como o da Diretoria, são fontes importantes na análise das transformações culturais nas organizações, não tanto pelo que revelam, mas principalmente pelo que procuram ocultar e dissimular. Esses discursos, impregnados de significações, tendem a (re)criar, ao longo da história da empresa, na rede de relacionamentos construídos pelos atores organizacionais, possíveis significados diferentes para o tema empregabilidade.

Particularmente, o tema empregabilidade aparece nos discursos da alta administração em momento de mudanças dentro da empresa. Na verdade, os altos dirigentes estavam buscando mudar a imagem da organização, transformandoa de empresa de engenharia em empresa de serviços de telecomunicações. Nos fragmentos discursivos analisados, começa-se a mostrar que não haveria mais garantia do emprego (Linha Direta, 1994): 
“é importante entender que nenhuma empresa, por si só, pode garantir empregos. Esta garantia está cada vez mais no mercado, na capacidade de manter os clientes satisfeitos. É isso que vai assegurar os resultados de que a empresa precisa para manter empregos, para investir e crescer”.

É interessante observar que a resposta à garantia de emprego está atribuída ao mercado: diretamente proporcional à satisfação dos clientes. Apesar de se tratar de empresa pública, onde a maioria das pessoas entrara por concurso e usufruía, ainda naquele momento, da estabilidade, a Diretoria já passava a afirmar a nãogarantia de empregos.

Uma vez encantado o cliente, haveria

“emprego, recompensa e reconhecimento compatíveis com a contribuição prestada, oportunidade de crescimento pessoal, profissional e desenvolvimento de habilidades; oportunidade de participar do desenvolvimento de uma empresa vigorosa, ética e transparência no relacionamento” (Construindo a Transformação, 1995).

É interessante destacar a união dos temas de emprego e reconhecimento combinados. A idéia já era mostrar que o funcionário teria emprego e recompensa compatível na proporção da satisfação do cliente. Junto a essa satisfação permanente dos consumidores (além de recompensas e oportunidades aos empregados), havia a proposta da empresa em "construir um projeto de melhoria focalizada nos processos de gerência e desenvolvimento de RH, adotando as melhores práticas de valorização e retenção dos talentos, de forma a viabilizar medidas de sustentação em curto prazo ao processo de Transformação Telemig” (Construindo a Transformação, 1995). E, ainda, que

“em um futuro próximo, manter a “sua” empregabilidade será essencial para a sobrevivência da Telemig. [...] Caberá ao empregado a preocupação também com sua formação, pois esta se refletirá na melhoria dos serviços da empresa. [...] Essa preocupação constante na busca de novos conhecimentos será sempre valorizada pela Diretoria da empresa e sua política de retenção dos novos talentos” (DDdicas, 1994).

Nos fragmentos acima, é possível inferir um tema implícito, a manutenção das pessoas talentosas (e, em contrapartida, a demissão dos não-talentosos), tema que será reelaborado e até mesmo explicitado para os empregados, sob a forma da empregabilidade. Pode-se também observar pela primeira vez na empresa, no fragmento discursivo acima, uma menção direta ao vocábulo empregabilidade. Além disso, esta nova nomenclatura trazia junto temas como o da manutenção do emprego e da busca constante de conhecimentos. A noção de empregabilidade 
parece, como afirma Menegasso (1998), confundir-se com a de competência e tem como referencial o indivíduo, seu conhecimento.

Abordagem semelhante pode ser apontada na observação de outras organizações, como acontece, a título de ilustração, na Rhodia S/A. Segundo Rios e Teixeira (1997), a empresa, tanto quanto as demais instaladas no Brasil, vem enfrentando nova ordem econômica e preparando-se para esse processo de mudança e turbulência crescentes. Além de uma série de ações localizadas, a organização centrou-se na questão da educação e treinamento, tendo em vista a necessidade de "adotar novos processos de aquisição de conhecimentos" (Rios e Teixeira, 1997, p. 262). Seu primeiro movimento foi "criar um ambiente de aprendizagem contínua [...], chamado Projeto Rhodia de Desenvolvimento da Empregabilidade" (Rios e Teixeira, 1997, p. 263), baseando-se no conceito de co-responsabilidade, no qual cada ator tem seus papéis e responsabilidades definidos, com a premissa de um projeto tripartite: empresa, empregados e sindicato, e a criação de um instrumento de medição de graus de empregabilidade que pudesse servir como bússola aos empregados e à empresa.

\section{Segunda Fase: Empregabilidade como Tema Compartilhado pela Alta Administração e pela Gerência}

Esta segunda fase abarca o período julho/agosto de 1995 a julho de 1998, descrito como sendo a fase da pré-privatização, em que a Diretoria - indicada pelos governos federal e estadual - busca implementar e aprofundar algumas transformações para tornar a Telemig mais rentável e, portanto, mais interessante aos possíveis novos proprietários. O tema do livre mercado mundial, segundo autores como Gray (1999), é, antes de tudo, um projeto político do fim do século e advém da experiência neoliberal que tem sido impulsionada pelo processo de globalização. O discurso hegemônico cultiva, entre outros temas, os da razão, da excelência, do Estado mínimo, da liberação da economia, da abertura comercial e desregulamentação e transferência das empresas públicas produtivas para o setor privado.

Para a alta administração da empresa, era preciso, aos poucos, mostrar que, quando privatizada, a empresa teria novas necessidades.

“A questão da empregabilidade é um discurso que a gente vem fazendo desde antes da privatização: que a sociedade não garante mais empregos, que as pessoas têm uma responsabilidade pessoal com sua empregabilidade. Então você tem que ter a responsabilidade de saber, de precisar estar melhorando as suas habilidades profissionais e sendo mais eclético" (Diretor). 
Percebe-se, no discurso da Direção, que as justificativas para as possíveis demissões eram: não-empregabilidade; falta de empenho de cada indivíduo no sentido de melhorar, de buscar coisas novas, de ser mais eclético, multifacetado. A perda do emprego era atribuída ao sujeito que não buscou aprimorar-se e acompanhar as mudanças para sua sobrevivência.

Neste sentido, com relação ao tema empregabilidade, Sarsur (1997) refere-se à tendência de o empregado buscar expandir suas alternativas de obter trabalho e remuneração sem a preocupação de trabalhar com vínculos empregatícios. No caso específico da Diretoria da Telemig, ela estaria exigindo que os empregados agissem como fornecedores de serviços e adotassem perfil mais autônomo, inovador, cooperador e flexível, características que, de acordo com Sarsur (1997), são indicadas pelo mercado como desejáveis para que os indivíduos permaneçam empregados. Além do mais, continua a autora, implicitamente, o que é dito é que o indivíduo deve ter como meta não mais possuir emprego e salário, mas trabalho e remuneração constantes, ter a capacidade de tornar-se empreendedor de si mesmo. Nesse sentido, quando a Diretoria explora o tema empregabilidade, está mostrando, indiretamente, as novas condições para os empregados da Telemig continuarem trabalhando na nova empresa após a privatização.

Nesta segunda fase, a Diretoria promove a circulação interna de um documento - não divulgado externamente - que convidava as pessoas para que procurassem “conhecer os objetivos estratégicos do Plano de Negócios da Telemig 1996-1998” (Plano de Negócios, 1996).

O Plano de Negócios estabelecido sintetizava, conforme a visão da alta administração:

“a estratégia de uma gestão do nosso tempo, consciente de que a ousadia dos sonhos atuais só se concretizará na medida de nossa eficiência no planejamento e ação. Planejar é ter competência para identificar dificuldades, perceber oportunidades de negócios e anseios legítimos da comunidade”.

No discurso sobre o Plano de Negócios também figuram as obrigações, tanto da Diretoria como dos empregados: mesclam-se Diretoria, funcionários e empresa em uma só personagem - nós. Tal fato é claramente identificado no documento, em passagens como:

"precisamos conquistar clientes todos os dias. [...] Nossa ação requer permanente inovação e não apenas respostas às pressões do ambiente. Temos que encantar e cativar nossos clientes. [...] Nossa intenção estratégica é garantir soluções integradas de telecomunicações a preços 
competitivos, com qualidade, tempo e local determinados pelos clientes, assegurando rentabilidade aos acionistas” (Plano de Negócios, 1996).

Consta desse documento interno (Plano de Negócios, 1996) uma chamada para que os indivíduos adquiram nova postura:

"precisamos de uma nova postura: ser positivos: para vencer é necessário acreditar; atuar em equipe: unir esforços para superar barreiras e alcançar melhores resultados; conquistar o cliente: esforçar-nos ao máximo para superar suas expectativas; [...] flexibilidade: ser flexíveis às mudanças [...]; compromisso: executar nossas funções com entusiasmo, iniciativa e responsabilidade. Agora, mais do que nunca, temos que trabalhar com espírito de equipe, com energia, vontade, para garantir o sucesso da Telemig”.

Os funcionários são levados não somente a acreditar, mas também a comprometer-se com a visão de mundo da alta administração, cumprindo as novas funções determinadas pela Diretoria com entusiasmo, vontade, iniciativa, energia e responsabilidade. Flexibilidade é um dos elementos mais importantes dessa visão, pois é preciso adaptar-se às mudanças. Por fim, uma proposta de permanente auto-análise encerra o documento.

"O que devemos nos perguntar sempre: de que forma estou contribuindo para o sucesso do Plano de Negócios da Telemig?; qual é o meu nível de comprometimento?; existe algo mais que eu possa fazer para melhorar a imagem e o desempenho da Telemig?; o que tenho feito para me aprimorar?; como posso melhorar minha produtividade e a da minha equipe?; onde quero chegar?; como vou chegar?” (Plano de Negócios, 1996).

Propõe-se, portanto, que as pessoas se questionem sobre sua conduta na empresa, o nível de sua contribuição e seu comprometimento com o sucesso da empresa.

Os temas do bom desempenho e da alta produtividade aparecem associados ao da empregabilidade. Pode-se observar que esse último tema começa aos poucos a ser introduzido também para os demais empregados. Cabe ao gerente a avaliação do funcionário, medindo desempenho e produtividade, que acabariam resultando em medidas de sua empregabilidade. É quase somatório matemático de um mais um igual a dois.

Outro aspecto que vale ressaltar no Plano de Negócios é que em seus objetivos estratégicos está representada a nova ordem dos saberes que, a partir de então, prevaleceriam na Telemig, conforme demonstra a Figura 1. 


\section{Figura 1: A Satisfação do Cliente e os Novos 'Poderes' na Telemig}

\section{SATISFAÇÃO DO CLIENTE}

O alcance dos objetivos estratégicos depende da participação efetiva de todas as áreas da empresa.
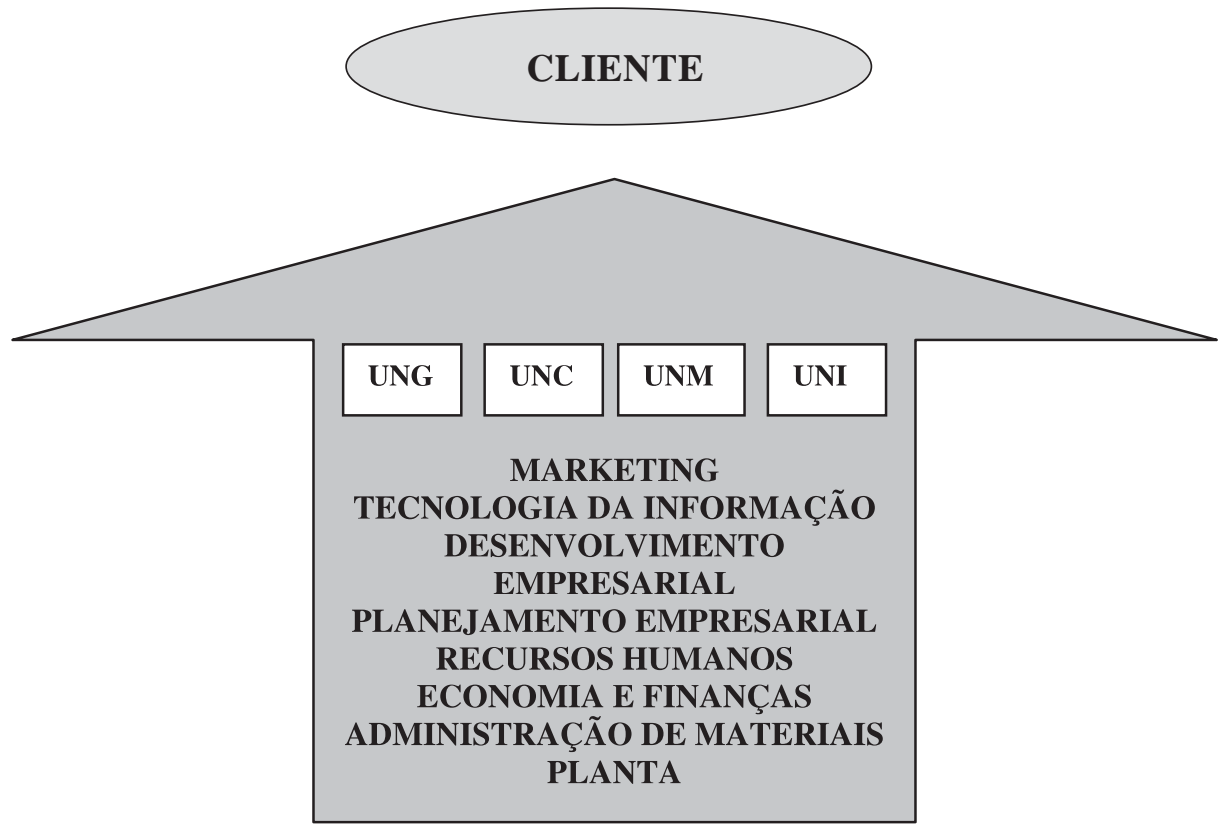

Fonte: adaptado de Plano de Negócios (1996).

Nessa figura, o cliente aparece como o centro do alvo. Logo depois, aparecem as áreas a partir daquele momento consideradas mais importantes, por estarem diretamente ligadas aos clientes. São as unidades de negócios que surgem com a reestruturação e, abaixo dessas áreas, são alistados, como seguindo uma hierarquia de importância, os conhecimentos considerados mais relevantes nessa nova fase da Telemig: marketing, tecnologia da informação, desenvolvimento empresarial, planejamento empresarial, recursos humanos, economia e finanças, administração de materiais e planta. Pode-se inferir uma concreta perda de poder do conhecimento técnico. Os empregados que tiverem conhecimentos não somente na área de engenharia, mas também na de administração ou economia, ou aqueles que buscarem essa formação, terão maiores chances de êxito e recompensas.

À medida que a privatização se aproximava, a empresa, ou melhor, a Diretoria, buscava promover inúmeros treinamentos para os gerentes. As entrevistas 
coletadas não explicitam, mas começava a delinear-se verdadeira competição entre as pessoas, na busca de conhecimentos que pudessem garantir a permanência dos gerentes nos seus respectivos cargos e empregos. Dessa forma, juntamente com os treinamentos emerge, nas gerências, o tema empregabilidade:

"nós precisávamos começar a trabalhar maciçamente em nossa empregabilidade, para que no dia em que chegasse essa empresa aqui, fosse como se a gente estivesse se candidatando a um emprego novo. Mas isso é muito difícil de ser colocado na cabeça das pessoas, não é? Muitas por comodidade, outras por não acreditarem, não percebem isso" (Gerente 7).

É a partir desta segunda fase que começa a esboçar-se um discurso que transfere a responsabilidade pela formação e treinamento dos empregados da empresa para o próprio indivíduo, auto-responsável por sua formação e manutenção de seu emprego. A ênfase na empregabilidade mostraria os novos tipos de papéis, comportamentos, imagens e identidades de que as pessoas necessitariam para permanecer na Telemig privatizada.

Nessa segunda fase, deve-se ressaltar também o papel do sindicato. É interessante destacar que, em decorrência principalmente das criativas charges que aparecem em seus jornais, esse grupo parece ter conseguido fazer surgir brechas no discurso da empregabilidade utilizado pela Diretoria. Observa-se, por exemplo, a Figura 2, em que a personagem principal aparece enquadrada, atrás das grades. A mensagem, tanto verbal como não-verbal, é bem forte, remetendo à pretensão da empresa/ Diretoria com relação ao perfil do profissional desejado: um bando de ovelhas, mais precisamente um bando de Dollys - a primeira ovelha clonada - ou um grupo homogêneo de soldados perfilados diante da suástica nazista.

\section{Figura 2: ‘Quem, eu?’ e a Padronização do Perfil Profissional dos Empregados}
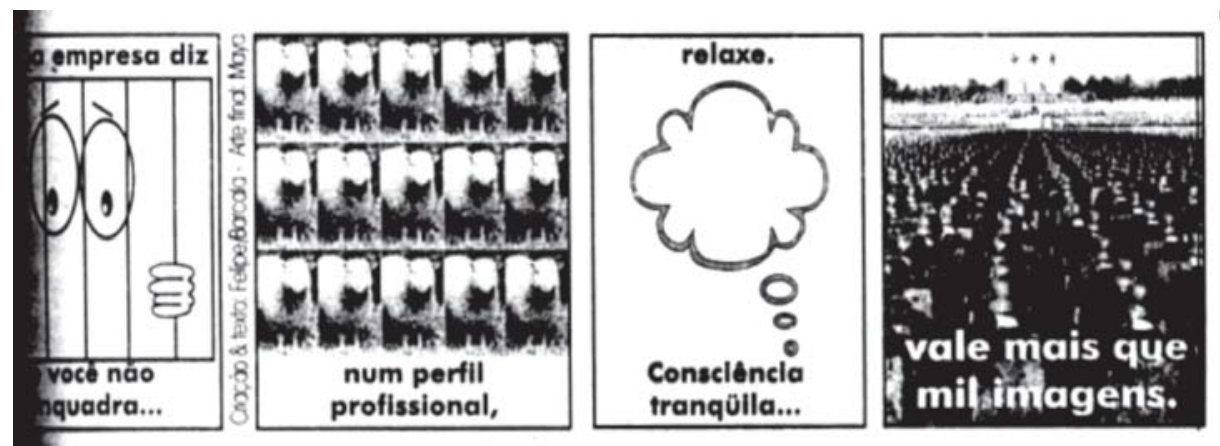

Fonte: Bodim (1997). 
Mediante reflexões propiciadas por muitas das charges, como a aqui mostrada na Figura 2, é que o sindicato foi, aos poucos, conseguindo influenciar muitos grupos da Telemig, incluindo os gerentes. Mostrando que o tema empregabilidade era usado como forma de adequar todos a um mesmo perfil profissional e que isso seria utilizado pela empresa para futuramente demitir os não-adequados, como implicitamente a mensagem traz: a idéia do nazismo, a perseguição a minorias (judeus, homossexuais etc). A mudança das ações deveria vir dessa nova e jovem base, apresentando-se uma visão de mundo no qual o trabalhador é ainda um assalariado e não um colaborador; em que a personagem coletiva (grupo) é mais importante que a personagem indivíduo; em que manter o número de empregos é mais importante que somente conquistar uma empregabilidade e supor garantias de estabilidade.

\section{Terceira Fase: Empregabilidade como Tema Disseminado entre Todos os Atores Organizacionais}

Esta fase analisa o período de julho de 1998 até 2000 da ex-Telemig ou atual Telemar-Minas. Nela percebe-se nas pessoas que trabalhavam na exTelemig uma grande ansiedade decorrente das mudanças realizadas, principalmente pela última Diretoria - 1995/1998 - a qual preconizava que, com a privatização, a empresa poderia ficar livre das amarras burocráticas, haveria autonomia estratégica, decisória e até operacional. Um discurso que prometia muita liberdade de fazer e acontecer. A liberdade, no entanto, na prática, estaria demorando, ou talvez nem viesse, porquanto, como se observa nas entrevistas, a empresa estaria se tornando uma filial de vendas e manutenção. Aos poucos, a ansiedade cedeu lugar ao medo, às frustrações e até ao sentimento de revolta.

Diante da demora de definição das estratégias da matriz, a nova Diretoria da Telemig, desde que tomou posse, procurou deixar bastante claro o que pretendia dos empregados e quais eram as estratégias da empresa. Não é à-toa que, na composição dessa alta administração, foram colocadas pessoas vinculadas à empresa (funcionários ou ex-funcionários). Em um DDdicas especial, a palavra estava com os diretores e o presidente:

“a DS [Diretoria de Serviços] deseja que os empregados, de forma geral, tenham maior poder e adaptabilidade aos novos tempos e às novas diretrizes. [...] "Para ela, é fundamental a valorização da produtividade de cada empregado. É necessário que todos tenham uma dose muito forte de iniciativa e criatividade, que são fatores de empregabilidade.” [...] Ele termina com um conselho e uma advertência: "Não há nada no mundo que não tenha alguém que faça melhor” (Diretor). 
No fragmento discursivo acima, pode-se observar que uma das personagens principais são os empregados. É a eles que o discurso é direcionado. Assim, aqueles que vestissem a camisa da empresa com dedicação absoluta e fizessem mais por ela, garantindo maiores ganhos aos acionistas, também receberiam mais. Assim, a empregabilidade já aparece freqüentemente nas falas dos diretores, como no fragmento discursivo a seguir.

“Na empresa agora é o seguinte: ela troca por uma qualidade melhor. Aquele profissional cuja atividade ou habilidade já não serve mais para desenvolver as atividades na empresa, ele vai ser trocado por um do mercado que está respondendo à nova tecnologia ou aos novos processos ou meios de gerenciamento, por aquele que tem melhor empregabilidade” (Diretor).

No entanto a disseminação do tema aparece também sob outras duas óticas distintas: a dos gerentes e a dos técnicos.

\section{A Empregabilidade e os Gerentes}

A mudança de empresa pública para filial de uma holding privada proporcionou aos gerentes o desenvolvimento de um novo foco de poder dentro da TelemarMinas. Esse novo foco estaria baseado no conhecimento. O domínio do conhecimento do mercado seria decisivo para que as pessoas se mantivessem na empresa.

Segundo os entrevistados, a estabilidade no emprego é quase diretamente proporcional aos conhecimentos adquiridos. Além disso, esses maiores conhecimentos que a pessoa possui possibilitam-lhe a manutenção de forte empregabilidade.

O discurso é bem explícito com relação à necessidade de não mais se esperar a oferta de formação profissional pela empresa, como antigamente ocorria, quando era pública e se preocupava com a melhoria da qualidade de seus recursos humanos. Agora, não se é mais um funcionário público, com a segurança de não perder o emprego, mas um cidadão do mundo, sem vínculo com as empresas, somente consigo mesmo e com o que se denomina mercado. A concepção de empregabilidade é também fortemente repassada aos demais empregados:

"então a gente tem que motivar muito, alertando para a questão da oportunidade, de se estar fazendo o serviço determinado, de se tornar competente para se estar no mercado. De se ter empregabilidade. Isso é um desafio muito grande, porque a maioria dos empregados, colaboradores, 
viram a média de quinze, vinte, vinte cinco anos de empresa. Eles vieram de uma empresa de monopólio, a empresa pública em que você se preparava para fazer uma carreira dentro da empresa, você não se preparava para estar no mercado. Hoje é o contrário” (Gerente 9).

O discurso dos gerentes é também repassado aos empregados com outro enfoque: se, para o grupo gerencial, o tema da empregabilidade está mais voltado para os conhecimentos adquiridos e para sua capacidade de gerir seus colaboradores, para os demais empregados esse tema tem que ver também com a produção individual, como se observa no depoimento "ele vai valer o que ele produz” (Gerente 41).

\section{A Empregabilidade e os Técnicos}

Para os técnicos, o emprego, na atual situação da empresa, atrela-se ao cumprimento das metas e também ao desenvolvimento do indivíduo. O tema empregabilidade ganha, assim, forte intensidade, segundo os técnicos, alguns dos quais chegam a assumir o discurso da alta administração nesse sentido. Vale ressaltar que há diversos matizes sobre o tema:

“a Telemar hoje é a realidade do mundo. Você tem que competir, acompanhar o desenvolvimento, cuidar da sua empregabilidade, senão você fica para trás. Isso não é a Telemar. Eu acho que é o mundo mesmo. Todas as empresas têm isso aí; não é competição, é a realidade, porque a concorrente que está chegando aí vai abocanhar o mercado" (Técnico 9).

A consciência de que se é descartável, somada às ambigüidades do discurso e das ações da alta administração, por não conseguir sequer esclarecer qual é a missão da empresa, qual é sua nova identidade, gera falas desta natureza:

“A gente está massificado, massacrado [...] Temos trabalhado, o nosso horário é de, no mínimo, dez horas por dia, o pessoal tem feito é dez, doze horas, quando não tem virado a noite” (Técnico 1).

“A gente está realmente numa postura de anticlímax, aguardando realmente para ver o que acontece. [...] O estresse aumentou por causa exatamente da concorrência. Já não estamos trabalhando com tanto prazer" (Técnico 12).

“É uma loucura o negócio [...] É uma incerteza, [...] as pessoas trabalham muito intranqüilas, muito inseguras, entendeu?” (Técnico 22). 
O massacre, o aumento do estresse, as exigências, as horas de trabalho, a dedicação fazem com que o que antes era prazeroso - trabalhar na Telemig - se torne na Telemar-Minas uma loucura, um anticlímax, criando entre os técnicos forte sentimento de insegurança e medo. Além desses temas ilustrativos do que pensam alguns técnicos sobre a administração da Telemar - holding e regional - há o sentimento de que trabalhar na ex-Telemig virou uma guerra de pessoa contra pessoa; a idéia da empregabilidade voltada para o próprio indivíduo acirra os ânimos, o colega deixa de ser colega e passa a ser concorrente; o grupo, a família que cuidava de todos deixa de existir, passando cada um a cuidar de si.

O grupo dos técnicos é consensual no entendimento de que a empresa tinha, no passado, uma cultura que privilegiava valores tais como: ser uma grande família, uma mãe; cultivo de valores grupais ligados à coletividade; incentivo ao saber técnico, considerado por esse grupo de pessoas ainda muito importante, mesmo em uma empresa onde os valores econômicos e individuais cada dia são mais exaltados. Alguns técnicos, lamentando a perda de identificação, externaram negação em vestir a camisa e insistiam na constante comparação entre a Telemig e a Telemar-Minas.

\section{À Guisa de Conclusões}

Entendendo a dinâmica de tais transformações como processo sistêmico, podese inferir que o que muda não são somente as relações entre as pessoas, mas também, e a partir delas, as organizações em sua inter-relação com o macroambiente. Sob esse aspecto, a concepção de empregabilidade surge como forma de consolidar ou nomear as alterações percebidas nesse universo, em especial nos últimos anos.

O discurso dominante tem procurado criar a homogeneização tanto dos símbolos, dos valores, das visões de mundo, como também da maneira de gerir as organizações, acabando por constituir-se em forte influenciador dos aspectos simbólico-culturais das identidades das organizações. Nos discursos, são veiculados não apenas sistemas de valores, racionalizações, justificativas, explicações, mas também comportamentos desejáveis e indesejáveis. A aprendizagem dessas regularidades e sua incorporação nos discursos dos atores sociais e organizacionais, para este trabalho, está estreitamente vinculada à produção de nova identidade organizacional (de empresa privada). Os discursos que permeiam a organização assimilam ou não aspectos de um discurso que vai fundamentar sua transformação.

Observa-se uma imposição da alta administração da empresa, já em vias de ser 
privatizada, ou seja, uma adequação ao discurso fundador. Desse modo, sob um plano simbólico, surgem temas como as vantagens de se pertencer ao mundo privado (e livre) e as desvantagens decorrentes do mundo público (e burocrático), tais como: competição; qualidade dos serviços e produtos; organizações flexíveis, criativas e enxutas; empregabilidade dos indivíduos. Esses temas e outros são reelaborados e introduzidos na empresa estudada pela alta administração. Com este estudo diacrônico sobre um período de aproximadamente dez anos, pode-se verificar a reelaboração desse discurso. Como é o caso, por exemplo, do tema estudado da empregabilidade. Ele é, inicialmente, mencionado em pouquíssimas falas - quase exclusivamente no âmbito da alta administração da empresa - no começo dos anos 1990; depois, entre 1995/1998, é incorporado pela Diretoria da empresa e já por alguns gerentes; e, por fim, após 1998, este tema percorre a organização quase verticalmente. Já no plano concreto, realizam-se vários projetos, objetivando a paulatina modernização da empresa e o enxugamento do corpo de empregados, para torná-la mais rentável e lucrativa. Com esse objetivo é que aparecem os projetos da qualidade total, da reengenharia e da transformação da Telemig (em 1990/1995), da reestruturação (em 1995/1998), e de várias pequenas reorganizações após a privatização.

Outrossim, pode-se observar que o percurso semântico do tema empregabilidade evidenciou o enfraquecimento progressivo do pacto da estabilidade-fidelidade entre os empregados (principalmente os técnicos) e a empresa. Com a assimilação do discurso da empregabilidade, valores como o da competição, da individualidade, temas da não-identificação, de Você S.A., são incorporados por grande parte dos atores organizacionais, que acabam por sujeitar-se ao discurso da alta administração e do mercado. A empregabilidade acaba tornando-se tema perseguido, muitas vezes confundido com o tema das novas competências, em que se misturam obrigações pessoais (com a sua formação), novos conhecimentos adquiridos (que valendo ouro não devem ser compartilhados com os outros e até com a organização), maior exploração por parte da empresa (dedicação), maiores controles (medição do desempenho), tendência crescente à maior fragmentação do trabalho dos profissionais (evitando que a empresa fique na mão de seus empregados) etc. Aos poucos, a empresa identificada nos discursos analisados como grande família, ou mãe, acaba por tornar-se grande madrasta, sanguessuga, a Telemá.

Com efeito, incentivam-se pessoas a adquirirem competências e a desenvolverem sua capacidade de aprendizagem, tornando-as demissíveis em seguida. Além disso, a empresa exige dedicação total dos empregados, demandando abdicação do descanso, da convivência com a família, de sua vida pessoal, e até do investimento em aprimoramento profissional, sem a correspondente contrapartida em termos de compromisso com relação à estabilidade no emprego. $\mathrm{O}$ posicionamento da organização é o de que aqueles que não conseguem manter o 
seu trabalho são responsabilizados por isso com a demissão e, além de se sentirem incompetentes, também são assim tratados pelo mercado, que os marginaliza, nisso corroborando os resultados obtidos por Luz (2001).

\section{Notas}

${ }^{1} \mathrm{O}$ termo significações é usado com referência ao discurso, em vez do termo significado, que faz referência ao vocábulo, ao signo (Saussure, 19-).

${ }^{2}$ Trata-se, em especial, de trabalhos que acabam por indicar as dificuldades de inserção no mercado e os procedimentos mais corretos para conseguir um novo trabalho, como se constata na mídia e jornais de grande circulação, além de autores como Rifkin (1995).

${ }^{3}$ Servem como referência, entre outros, os trabalhos de Minarelli (1995), Case (1997a, 1997b), Pereira (1997), Saviani (1997).

\section{ReferênCias Bibliográficas}

\section{BERNARDES, R.}

Trabalho: a centralidade de uma categoria analítica. São Paulo em Perspectiva, v. 8, n. 1, p. 33-41, jan./mar. 1994.

BODIM SEMANAL.

Belo Horizonte: Sinttel, 1997.

\section{BRIDGES, W.}

Um mundo sem empregos. São Paulo: Makron Books, 1995.

\section{CASE, T.}

Empregabilidade. São Paulo: Makron Books, 1997a.

Como conquistar um ótimo emprego. São Paulo: Makron Books, 1997b.
CONSTRUINDO A

TRANSFORMAÇÃO.

Belo Horizonte: Telemig, 1995.

DDDICAS. Belo Horizonte: Telemig, jan.-dez. 1994.

DU GAY, P.;

SALAMAN, G.;

REES, B.

The conduct of management and the management of conduct. Journal of Management Studies, v. 33, n. 3, p. 263-282, 1996. 
FARIA, A. A.M.

Interdiscurso, intradiscurso e leitura: o caso de Germinal. In: MARI, H.; MACHADO, I. L.; MELLO, R. (Orgs.). Análise do discurso: fundamentos e práticas. Belo Horizonte: Núcleo de Análise do Discurso/Fale/UFMG, 2001.

Sobre o Germinal: Interdiscurso, intradiscurso e leitura. São Paulo, 1999. Tese (Doutorado) Universidade de São Paulo.

FIORIN, J. L.

Elementos de análise do discurso. São Paulo: Contexto, 1989.

Linguagem e ideologia. São Paulo: Ática, 1988.

FLEURY, M. T. L;

SHINYASHIKI, G.;

STEVANATO, L.A.

Entre a antropologia e a psicanálise. Revista de Administração de Empresas, v. 37, n. 1, p. 23-37, 1997.

FREITAS, M. E.

Contexto social e imaginário organizacional moderno. Revista de Administração de Empresas, n. 2, p. 6-15, 2000.

GITAHY, L.;

FISCHER, R. M.

Produzindo a flexibilidade. Trabalho apresentado no 2.
Congresso Latino-Americano de Sociologia do Trabalho, São Paulo, 1996. mimeo.

GRAY, J.

Falso amanhecer: os equívocos do capitalismo global. São Paulo: Record, 1999.

\section{LINHA DIRETA.}

Belo Horizonte: Telemig, dez. 1994.

\section{LUZ, T. R.}

T E L E M A R - M i n a s : competências que marcam a diferença. Belo Horizonte, 2001. Tese (Doutorado em Administração) - Centro de PósGraduação e Pesquisa em Administração, Universidade Federal de Minas Gerais.

MENDONÇA, S.

Globalização, tecnologia e relações de trabalho. Estudos Avançados, v. 11, n. 29, p. 375-378, jan./abr. 1997.

MENEGASSO, M. E.

O declínio do emprego e a ascensão da empregabilidade: um protótipo para promover condições de empregabilidade na empresa pública do setor bancário. Florianópolis, 1998. Tese (Doutorado) - Universidade Federal de Santa Catarina. 
MINARELLI, J. A.

Empregabilidade: o caminho das pedras. São Paulo: Gente, 1995.

PEREIRA, P.

Enfrentando o mercado de trabalho: orientações para um posicionamento mais adequado para os tempos atuais. São Paulo: Nobel, 1997.

PLANO DE NEGÓCIOS 19961998. Belo Horizonte: TELEMIG, 1996.

RIFKIN, J.

O fim dos empregos. São Paulo: Makron Books, 1995.

RIOS, I.;

TEIXEIRA, J. E.

Projeto Rhodia de desenvolvimento da empregabilidade. In: CASALI, A. et al. (Orgs.). Empregabilidade e educação. São Paulo: EDUC, 1997.
RODRIGUES, S. B.;

CARRIERI, A. P.;

LUZ, T. R.

Competição organizacional: bricolagens simbólicas In: RODRIGUES, S. B.; CUNHA, M. P. (Orgs). Estudos organizacionais: novas perspectivas para a administração de empresas. São Paulo: Iglu Edições, 2000.

SARSUR, A. M.

Empregabilidade $\mathrm{x}$ empresabilidade: novas práticas em recursos humanos? In: ENCONTRO ANUAL DA ANPAD, 21., 1997, Angra dos Reis. Anais... Rio de Janeiro: ANPAD, 1997. 1 CD-ROM.

SAUSSURE, F.

Curso de lingüística geral. São Paulo: Cultrix, 19—.

SAVIANI, J. R.

Empresabilidade. São Paulo: Makron Books, 1997.

SCHUTZ, A.

Fenomenologia e relações sociais. Rio de Janeiro: Zahar, 1979. 